\title{
Kotimainen herne sinikettujen rehussa
}

\author{
Nita Koskinen ${ }^{1)}$, Juhani Sepponen ${ }^{1)}$, Ilpo Pölönen ${ }^{2)}$ ja JarmoValaja ${ }^{3)}$ \\ ${ }^{1)}$ Maa-ja elintarviketalouden tutkimuskeskus, Kotieläintuotannon tutkimus, Turkistalous, 69100 Kannus, \\ etunimi.sukunimi@mtt.fi \\ ${ }^{2)}$ Suomen Turkiseläinten Kasvattajain Liitto ry, PL 5, 01601 Vantaa ilpo.polonen@stkl-fpf.fi \\ ${ }^{3)}$ Maa-ja elintarviketalouden tutkimuskeskus, Kotieläintuotannon tutkimus, Eläinravitsemus, 31600 \\ Jokioinen, jarmo.valaja@mtt.fi
}

\section{Tiivistelmä}

Rehuvalkuaisen omavaraisuus EU:ssa ja Suomessa on vain 30 prosenttia. Tärkein rehuvalkuaisen lähde on tuontisoija. Kiinnostus herneen käyttöön kotieläinten valkuaisrehuna on lisääntynyt mm. EU:n lihaluujauhon käyttökiellon myötä. Kasvivalkuaisen käyttöä myös turkiseläinten, erityisesti sinikettujen, rehussa on mahdollista lisätä, koska valkuaisen määrää rehussa on voitu alentaa. Näin ollen rehun valkuaislisien ei tarvitse olla runsasvalkuaisia. Herneen käyttökelpoisuutta siniketun rehuraaka-aineena ei ole aikaisemmin tutkittu.

Tutkimuksessa selvitettiin herneen tuotantovaikutuksia kasvavilla siniketuilla loppukasvatuksen aikana. Lisäksi selvitettiin hernelisäyksen vaikutuksia rehun sulavuuteen.

Koe toteutettiin MTT:n turkistutkimusasemalla Kannuksessa 75 sinikettu-uroksella. Käsittelyitä oli viisi (15 eläintä/ryhmä). Koemallina oli jatkuva kasvatuskoe, johon sisältyi merkkiainemenetelmällä tehty sulavuuskoe. Koerehuissa esikypsennetty ohra (EO) ja soijarouhe (SR) korvattiin asteittain raa'alla tai kypsällä herneellä: 1) 12 \% EO + 6 \% SR, 2) 9\% EO + 4,5\% SR + 4,5 \% raakaa hernettä, 3) 6\% EO + 3 \% SR + $9 \%$ raakaa hernettä, 4) 9\% EO + 4,5 \% SR + 4,5 \% kypsää hernettä, 5) 6\% EO + 3 \% SR + $9 \%$ kypsää hernettä. Tutkittavina muuttujina olivat eläinten kasvu ja rehunkulutus, rehujen sulavuus, nahkojen laatu ja pituus.

Siniketut kasvoivat hyvin kaikilla rehuilla. Eroja koeryhmien välille ei syntynyt kasvussa eikä rehunkulutuksessa. Kaikkien rehujen raakavalkuaisen ja raakarasvan sulavuudet olivat hyviä, 76,1-78,4\% ja 89,7-92\%, eikä tilastollisia eroja ryhmien välillä ilmennyt. Sen sijaan hiilihydraattien sulavuuksissa oli selviä eroja. Sulavuus oli korkein kontrollirehussa, 64,5 $\pm 1,0 \%$, joka sisälsi ainoastaan esikypsennettyä ohraa ja soijarouhetta, matalin, 46,8 $\pm 1,6 \%$, rehussa, joka sisälsi $9 \%$ raakaa hernettä. Nahkojen pituudessa tai laadussa ryhmät eivät poikenneet toisistaan.

Tämän kokeen perusteella kypsä herne on käyttökelpoista siniketun rehuraaka-ainetta, vaikka sen raakahiilihydraattien sulavuus olikin hieman kontrollirehua heikompi. Raa'an ja kypsennetyn herneen valkuainen ja rasva sekä kypsennetyn herneen hiilihydraatit ovat hyvin sulavia. Herneen kypsennys nostaa kuitenkin raaka-ainekustannuksia. Mikäli kotimaisen herneen rehuhinta on kilpailukykyinen, se voi korvata muita valkuaisraaka-aineita kuten tuontisoijaa.

Asiasanat herne, sinikettu, kasvivalkuainen, sulavuus 


\section{Johdanto}

Rehuvalkuaisen omavaraisuus EU:ssa ja Suomessa on vain 30 prosenttia. Tärkein rehuvalkuaisen lähde on tuontisoija. Valkuaisrehun hinnat kohoavat kysynnän lisääntymisen myötä.

Herneen viljelyä tehostamalla ja varmentamalla kyettäisiin poistamaan tuontivalkuaisriippuvuutta. Kansantaloudellisesti olisikin järkevää korvata tuontivalkuaista kotimaisilla kasvivalkuaislähteillä kuten palkokasveilla. Herne on kasvina sopeutunut hyvin viileään ilman alaan ja on hyvä valkuais- ja hiilihydraattilähde. Herneen viljelyvarmuutta ja viljelyn kannattavuutta on pystyttävä parantamaan, jotta kiinnostus herneen viljelyyn saadaan elpymään. Herneen rehuarvon tarkempi määritys ja tuotantoon kehitettävät sopimusmallit voivat viljelyteknisten toimenpiteiden ohella luoda edellytyksiä rehuherneen kannattavalle viljelylle.

Kiinnostus herneen käyttöön kotieläinten valkuaisrehuna on lisääntynyt mm. EU:n lihaluujauhon käyttökiellon myötä. Kasvivalkuaisen käyttöä myös turkiseläinten, erityisesti sinikettujen, rehussa on mahdollista lisätä, koska silakan ja teurassivutuotteiden saatavuus on heikentynyt viime aikoina. Herneen käyttökelpoisuutta sinikettujen rehuna ei ole aikaisemmin tutkittu. Lämpökäsitellyn tai ekstruuderoidun herneen käyttöä minkinrehun raaka-aineena on tutkittu aikaisemmin (Bjergegaard et al. 1995, Clausen \& Therkildsen 1995, Ahlstrøm \& Skrede 2003).

Tutkimuksen tavoitteena oli selvittää rehuherneen soveltuvuutta turkiseläinten tuotantokauden rehun raaka-aineena. Tutkimuksessa selvitettiin herneen tuotantovaikutuksia kasvavilla siniketuilla loppukasvatuksen aikana. Lisäksi selvitettiin hernelisäyksen vaikutuksia rehun sulavuuteen.

\section{Aineisto ja menetelmät}

Koe toteutettiin 4.9.-17.11.2003 MTT:n turkistutkimusasemalla Kannuksessa 75 sinikettu-uroksella. Käsittelyitä oli viisi (15 eläintä/ryhmä). Täysveljekset sijoitettiin jokaiseen koeryhmään. Eläimet kasvatettiin normaalikäytännön mukaisesti varjotalossa verkkopohjaisissa yksilöhäkeissä. Eläinten ikä oli kokeen alussa noin 3,5 kuukautta. Koemallina oli jatkuva kasvatuskoe, johon sisältyi sulavuuskoe. Koerehuissa esikypsytetty ohra ja soijarouhe korvattiin asteittain raa’alla tai kypsällä herneellä (taulukko 1):

1) Kontrollina $12 \%$ esikypsytettyä ohraa $+6 \%$ soija rouhetta

2) $9 \%$ esikypsytettyä ohraa $+4,5 \%$ soija rouhetta $+4,5 \%$ raakaa hernettä

3) $6 \%$ esikypsytettyä ohraa $+3 \%$ soija rouhetta $+9 \%$ raakaa hernettä,

4) $9 \%$ esikypsytettyä ohraa $+4,5 \%$ soija rouhetta $+4,5 \%$ kypsää hernettä

5) $6 \%$ esikypsytettyä ohraa $+3 \%$ soija rouhetta $+9 \%$ kypsää hernettä.

Muina rehun raaka-aineina käytettiin teurassivutuotetta, broilersivutuotetta, soijaöljyä, metioniinia (2 kg/tn rehua) ja hiven- sekä vitamiiniseosta. Hernettä keitettiin vedessä 20 min ajan. Keitetyn herneen vesipitoisuus otettiin huomioon rehulaskelmissa. Rehuihin lisättiin kaliumsorbaattia ja Vitaquinea parantamaan rehun säilyvyyttä. Rehut optimoitiin kasvavien kettujen tarpeiden mukaan ja ne sisälsivät n. $22 \%$ ME:stä valkuaisesta (taulukko 2). Rehut valmistettiin ennen kokeen alkua Kannuksen Minkinrehu Oy:ssä ja pakastettiin levypakastimella. Koerehuista kerättiin ruokinnan yhteydessä näytteet, joista määritettiin kuiva-aine kahden viikon välein.

Eläimiä ruokittiin kerran päivässä ruokahalun mukaan. Rehunkulutus mitattiin häkeittäin. Eläimet punnittiin kokeen alussa ja lopussa sekä kokeen aikana kahden viikon välein. Kokeen lopussa eläimet lopetettiin sähköllä ja nahkottiin. Nahkonnan jälkeen koenahkat kuivattiin. Raakanahkat mitattiin, punnittiin ja koearvosteltiin Turkistuottajat Oyj:ssä. Massa, puhtaus, peittävyys ja laatuluokka arvosteltiin Turkistuottajat Oyj:n lajittelijoiden toimesta asteikolla 1-10 (10 paras). Värilajittelussa käytettiin värilajittelukonetta, jonka antamat pikseliarvot on luokiteltu väriluokkiin 1-8 (8 vaalein). Väriluokan ero oli n. 35 pikseliä.

Tuotantokokeen aikana tehtiin sulavuuskoe 22. syyskuuta alkaen. Sulavuuskokeen aikana syötettävään rehuun sekoitettiin erikseen 0,5 \% piimaata merkkiaineena (Celite ${ }^{\circledR}$, Celite Corporation, Lompoc, CA, USA). Merkkiaine määritettiin happoon liukenemattomana tuhkana (AIA). Eläimiä 
ruokittiin sulavuuskokeen rehuilla seitsemän päivän ajan ennen varsinaista keruujaksoa. Sonta kerättiin talteen jokaisen häkin viritetyltä verkolta viiden päivän ajalta. Näyte pakastettiin. Viikkoa ennen keruuta ja sen aikana eläimet saivat vakiomäärän rehua joka päivä. Eläimet punnittiin keruujakson alussa ja lopussa.

Tilastolliseen testaukseen käytettiin SAS:n (9.1) MIXED-proseduuria, jossa otettiin huomioon käsittely ja pentue. Parittaisvertailussa käytettiin Tukeyn korjauskerrointa.

Taulukko 1. Koerehujen raaka-aineet, \%

\begin{tabular}{lccccc}
\hline & Kontrolli & Raaka 4.5 \% & Raaka 9.0 \% & Kypsä 4.5 \% & Kypsä 9.0 \% \\
\hline Teurassivutuote, Pouttu & 41 & 40 & 40 & 41 & 40 \\
Broilersivutuote & 21 & 20 & 20 & 21 & 20 \\
Esikypsytetty Ohra, & 12 & 9 & 6 & 9 & 6 \\
Suomen Rehu & & & & 5 & 3 \\
Soijarouhe & 5 & 5 & 5 & 5 & 5 \\
Soijaöljy & 5 & 4,5 & 9 & 4 & 8 \\
Herne & 1 & 1 & 1 & 1 & 1 \\
STKL-vita & 14 & 16 & 16 & 14 & 16 \\
Vesi & & & &
\end{tabular}

Taulukko 2. Koerehujen analysoitu koostumus

\begin{tabular}{lccccc}
\hline & Kontrolli & Raaka $4.5 \%$ & Raaka 9.0 \% & Kypsä 4.5 \% & Kypsä 9.0 \% \\
\hline Kuiva-aine, \% & 41,0 & 41,5 & 42,5 & 42,1 & 40,0 \\
Rehussa: & & & & & \\
Tuhka, \% & 2,8 & 2,9 & 3,1 & 3,3 & 3,1 \\
Raakavalkuainen, \% & 11,4 & 10,6 & 10,6 & 10,9 & 10,5 \\
Raakarasva, \% & 12,3 & 13,6 & 14,7 & 13,7 & 12,8 \\
Raakahiilihydraatit, \% & 14,5 & 14,4 & 14,0 & 14,1 & 13,6 \\
ME MJ/kg & 7,9 & 8,2 & 8,5 & 8,3 & 7,8 \\
ME kcal/kg & 1879 & 1955 & 2041 & 1970 & 1863 \\
& & & & & \\
Kuiva-aineessa: & & & & & \\
Tuhka, \% & 6,8 & 7,0 & 7,4 & 7,9 & 7,6 \\
Raakavalkuainen, \% & 27,7 & 25,5 & 25,0 & 26,0 & 26,3 \\
Raakarasva, \% & 30,0 & 32,8 & 34,6 & 32,6 & 32,0 \\
Raakahiilihydraatit, \% & 35,5 & 34,8 & 33,0 & 33,5 & 34,1 \\
ME MJ/kg & 19,2 & 19,7 & 20,1 & 19,6 & 19,5 \\
ME kcal/kg & 4582 & 4710 & 4804 & 4681 & 4661 \\
& & & & & \\
Proteiinien osuus ME:sta, \% & 24,5 & 21,9 & 21,1 & 22,5 & 22,8 \\
Rasvan osuus ME:sta, \% & 56,0 & 59,5 & 61,6 & 59,5 & 58,7 \\
Hiilihydraattien osuus & 19,5 & 18,6 & 17,3 & 18,0 & 18,4 \\
ME:sta, \% & & & & & \\
\hline
\end{tabular}




\section{Tulokset ja tulosten tarkastelu}

Siniketut kasvoivat normaalisti kaikilla rehuilla (kuva 1). Keskipainot kokeen lopussa olivat 13,4-13,9 kg. Päivä- tai suhteellisessa kasvussa sekä rehunkulutuksessa ei ollut eroja ryhmien välillä. Kokeen aikana päivittäinen keskirehunkulutus oli 792-839 g.

Sekä kontrolli- että hernerehuissa raakavalkuaisen ja raakarasvan sulavuus (76,1-78,4\% ja 89,7-92\%) olivat hyviä (taulukko 3). Hiilihydraattien sulavuus oli korkein kontrollirehussa $(64,5 \pm 1,0$ $\%$, joka sisälsi ainoastaan esikypsytettyä ohraa ja soijarouhetta. Huonoin hiilihydraattien sulavuus $(46,8 \pm 1,6 \%)$ oli rehussa, joka sisälsi $9 \%$ raakaa hernettä. Ilmeisesti sinikettu ei pysty käyttämään suuressa määrin raa'an herneen hiilihydraatteja yhtä tehokkaasti hyväkseen kuin valmiiksi kypsytetyn herneen hiilihydraatteja. Siniketuilla kypsennetyn herneen rasva, valkuainen ja hiilihydraatit olivat hyvin sulavia. Herneen kypsennys nostaa kuitenkin raaka-ainekustannuksia.

Sinikettujen nahkat olivat samankokoisia, eivätkä nahkojen laatuominaisuudet eronneet ryhmien välillä (taulukko 4). Nahkojen keskipituus oli 124,4-126,8 cm.

Herneen käyttökelpoisuutta siniketunrehun raaka-aineena - erityisesti hernelisäyksen vaikutuksia rehun sulavuuteen - ei ole aikaisemmin tutkittu. Ahlstrømin ja Skreden (2003) mukaan minkinrehun raaka-aineena kasvukaudella voidaan käyttää jopa $15 \%$ ekstruderoitua hernettä ainoana hiilihydraattilähteenä eikä hernelisäyksellä havaittu negatiivisia vaikutuksia minkkien tuotantotuloksiin tai terveyteen. Herne on hyväksi havaittu turkiseläinrehun raaka-aine myös Tanskassa. Tanskassa käytetään ruokalaatuista lämpökäsiteltyä ja kuorettomana jauhettua hernettä minkin syysrehussa n. 5 \% (Lassen, 2002). Vaikka herneellä on tutkimusten mukaan positiiviset vaikutukset sekä minkin että siniketun tuotantotuloksiin, raaka-ainekustannukset ja saatavuus rajoittavat herneen käyttöä rehussa.

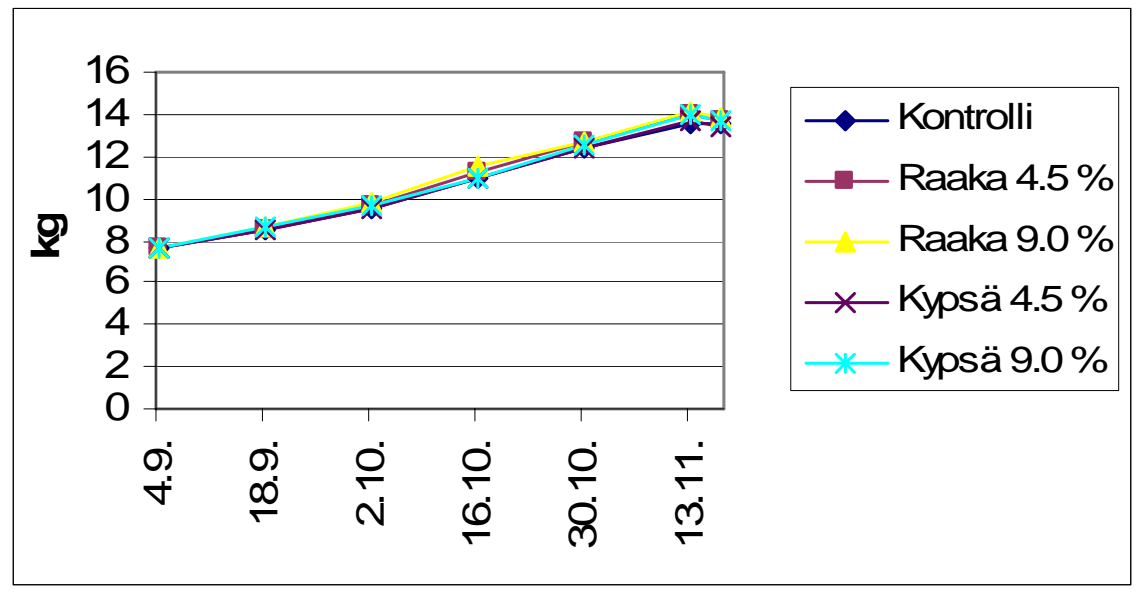

Kuva 1. Eläinten keskipainot $(\mathrm{kg})$ kokeen aikana

Taulukko 3. Koerehujen kuiva-aineen, tuhkan, orgaanisen aineen, raakavalkuaisen, -rasvan ja -hiilihydraattien sulavuudet $(\% \pm \mathrm{SE})$.

\begin{tabular}{lcccccc}
\hline & Kontrolli & Raaka 4.5 \% & Raaka 9.0 \% & Kypsä 4.5 \% & Kypsä 9.0\% & P* $^{*}$ \\
\hline Kuiva-aine & $71,38 \pm 0,60^{\mathrm{b}}$ & $71,80 \pm 0,90^{\mathrm{b}}$ & $67,52 \pm 0,94^{\mathrm{a}}$ & $69,14 \pm 0,58^{\mathrm{ab}}$ & $71,86 \pm 0,89^{\mathrm{b}}$ & $* * *$ \\
Tuhka & $18,07 \pm 1,61^{\mathrm{a}}$ & $26,73 \pm 0,82^{\mathrm{b}}$ & $13,67 \pm 1,79^{\mathrm{a}}$ & $15,68 \pm 1,07^{\mathrm{a}}$ & $26,97 \pm 1,74^{\mathrm{b}}$ & $* * *$ \\
Orgaaninen aine & $76,21 \pm 0,62^{\mathrm{b}}$ & $76,02 \pm 0,93^{\mathrm{b}}$ & $72,05 \pm 0,92^{\mathrm{a}}$ & $74,17 \pm 0,62^{\mathrm{ab}}$ & $76,03 \pm 0,84^{\mathrm{b}}$ & $* * *$ \\
Raakavalkuainen & $76,78 \pm 0,67$ & $77,97 \pm 1,03$ & $76,16 \pm 0,83$ & $76,09 \pm 0,72$ & $78,41 \pm 0,77$ & \\
Raakarasva & $89,67 \pm 0,53$ & $90,91 \pm 0,67$ & $90,96 \pm 0,98$ & $89,58 \pm 0,76$ & $91,98 \pm 0,73$ & \\
Raakahiilihydraatit & $64,46 \pm 0,95^{\mathrm{c}}$ & $59,19 \pm 1,37^{\mathrm{b}}$ & $46,83 \pm 1,64^{\mathrm{a}}$ & $56,87 \pm 0,80^{\mathrm{b}}$ & $57,02 \pm 1,66^{\mathrm{b}}$ & $* * *$ \\
\hline
\end{tabular}

Kontrastit RH: Kontrolli vs. muut $\mathrm{P}<0.001$, raaka vs. kypsä $\mathrm{P}<0.01,4.5$ \% vs. 9 \% $\mathrm{P}<0.001$ 
Taulukko 4. Nahkojen pituus (cm), paino (g) ja laatupisteet (massa, puhtaus, peittävyys, yleisvaikutelma, väriluokka ja väri pikseleinä) ( $\pm \mathrm{SE}$ ).

\begin{tabular}{lccccc}
\hline & Kontrolli & Raaka 4.5 \% & Raaka 9.0 \% & Kypsä 4.5 \% & Kypsä 9.0 \% \\
\hline Pituus, cm & $126,0 \pm 1,2$ & $125,9 \pm 1,4$ & $126,8 \pm 1,4$ & $124,4 \pm 1,6$ & $126,6 \pm 1,2$ \\
Paino, g & $828 \pm 24$ & $838 \pm 28$ & $837 \pm 24$ & $824 \pm 21$ & $808 \pm 23$ \\
Massa & $7,1 \pm 0,4$ & $7,1 \pm 0,5$ & $6,6 \pm 0,5$ & $6,9 \pm 0,4$ & $6,3 \pm 0,5$ \\
Puhtaus & $7,5 \pm 0,1$ & $7,6 \pm 0,1$ & $7,6 \pm 0,2$ & $7,7 \pm 0,1$ & $7,6 \pm 0,1$ \\
Peittävyys & $7,1 \pm 0,4$ & $6,6 \pm 0,4$ & $7,3 \pm 0,3$ & $6,9 \pm 0,4$ & $7,0 \pm 0,3$ \\
Yleisvaik. & $7,1 \pm 0,3$ & $7,1 \pm 0,3$ & $6,8 \pm 0,4$ & $6,7 \pm 0,4$ & $6,4 \pm 0,4$ \\
Väriluokka & $3,3 \pm 0,3$ & $3,4 \pm 0,4$ & $2,9 \pm 0,3$ & $3,3 \pm 0,3$ & $3,2 \pm 0,3$ \\
(8=vaalein) & & & & & \\
Pikselit & $323 \pm 12$ & $328 \pm 15$ & $308 \pm 12$ & $332 \pm 14$ & $318 \pm 17$ \\
\hline
\end{tabular}

\section{Johtopäätökset}

Kypsä herne on käyttökelpoinen siniketun rehuraaka-aine, vaikka raakahiilihydraattien sulavuus oli hieman kontrollirehua heikompi. Raa'an ja kypsennetyn herneen valkuainen ja rasva sekä kypsennetyn herneen hiilihydraatit ovat hyvin sulavia. Herneen kypsennys nostaa kuitenkin raakaainekustannuksia. Mikäli kotimaisen herneen rehuhinta on kilpailukykyinen, se voi korvata muita valkuaisraaka-aineita kuten tuontisoijaa. Myös tuontiherneen käyttöä turkiseläinrehun raaka-aineena tulisi harkita.

\section{Kirjallisuus}

Ahlstrøm, Ø. \& Skrede, A. 2003. Extruded peas as a feed ingredient for mink in the growth period. NJF-seminar no.354, Lillehammer, Norway. 8-10. October 2003.

Bjergegaard, C., Hilleman, G. \& Sørensen, H. 1995. Ærter I foder til mink. Faglig Årsberetning 1993/94, 39-48.

Clausen, T.N. \& Therkildsen, N. 1995. Anvendelse af byg og ærter samt blandninger af disse ved forskelligt kulhydratniveau til mink. Faglig Årsberetning 1993/94, 28-32.

Lassén, T.M. 2002 Vedrørende Suprex Pea 21 og Suprex Faba. Internt notat Landscentret Pelsdyr, Dansk Landbrugsrådgivning 2002. 